\title{
An analysis of changes to transit accessibility and equity after the opening of a bus rapid transit system in Hartford, Connecticut
}

\author{
Kelly Bertolaccini \\ The University of Queensland \\ k.bertolaccini@uq.edu.au
}

\begin{abstract}
In March 2015, CTfastrak, a bus rapid transit system operating in Connecticut in the United States, opened after nearly 16 years of planning and controversy. The 15.1-km (9.4-mi) busway connects the town of New Britain to the state capital of Hartford. The analysis conducted in this paper investigates whether or not CTfastrak and the transit system restructuring that occurred between 2013 and 2016 improved overall transit accessibility in the region, and if so, whether or not the distribution of these improvements is equitable. This exploration provides strong evidence that overall transit accessibility has improved in the region. Horizontal, or spatial equity, did worsen slightly as a result of this highly localized project. However, vulnerable populations experience more improvements and fewer decreases in transit accessibility than the general population. Though these analyses seem promising, an analysis of the distribution of transit access among workers hints that while many people are experiencing increases in general accessibility, they may not have meaningful access to their place of employment.
\end{abstract}

\section{Article history:}

Received: November 1, 2016

Received in revised form:

May 16, 2017

Accepted March 6, 2018

Available online: November 29, 2018

\section{Introduction}

After more than 15 years of planning, CTfastrak opened for passengers in March 2015 (Connecticut Department of Transportation, 2016). The $15.1 \mathrm{~km}$ (9.4 mi) long dedicated busway runs between the Hartford, the capital city of Connecticut (CT), USA, and New Britain, a smaller town to the southwest of the city. The bus rapid transit system was originally proposed by the Hartford West Major Investment Study in 1997 as a means of reducing congestion on the parallel I-84 freeway corridor and as a way to improve transit and alternative transport modes in the region (U.S. Department of Transportation, Federal Transit Administration, and Connecticut Department of Transportation., 2001). Figure 1 below shows the final busway alignment alongside the major interstates in the Hartford region

Copyright 2018 Kelly Bertolaccini

http://dx.doi.org/10.5198/jtlu.2018.1086

ISSN: 1938-7849 | Licensed under the Creative Commons Attribution - Noncommercial License 4.0

The Journal of Transport and Land Use is the official journal of the World Society for Transport and Land Use (WSTLUR) and is published and sponsored by the University of Minnesota Center for Transportation Studies. This paper is also published with additional sponsorship from WSTLUR. 


\section{CTFastrak Corridor: Hartford, CT, USA}

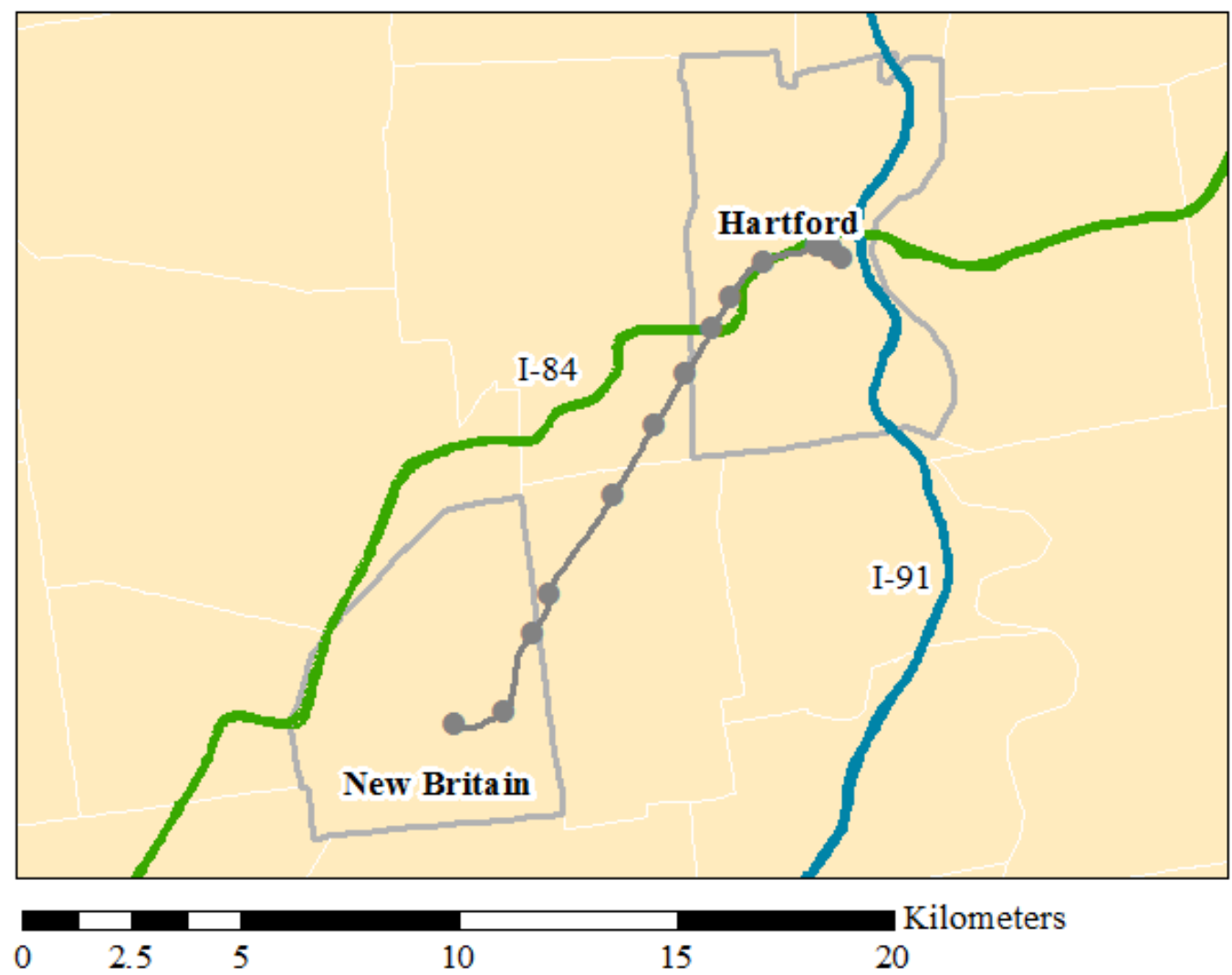

Figure 1: Map of the CTfastrak corridor alongside the I-84 and I-95 freeways

With a cost of $\$ 567$ million, $\$ 454.6$ million of which came from federal sources (Federal Transit Administration, 2015), this project generated controversy throughout the state. The local newspapers first announced the project to the public as an optimistic development for the state, reporting a cost of $\$ 75$ million and a completion date in the early half of the 2000's (Swift \& Good, 1999; Willingham, 2000). However, as the costs and delays increased and some locals realized the project might negatively affect their residential and business properties, the coverage became increasingly critical (Melone, 2006).

This paper seeks to establish whether CTfastrak and the accompanying service changes led to system-wide improvements in transit accessibility and, if so, how these improvements were distributed. This analysis will explore the equity of changes in accessibility and any spatial or demographic patterns that exist among the neighborhoods that lost or gained accessibility between May 2013 and May 2016, the timeframe of analysis. Rather than look at changes in general transit accessibility in isolation, this analysis will also look at equity in access to jobs.

\section{Methods and data}

Transit accessibility will be measured using the Transit Opportunity Index (TOI) (Bertolaccini, Lownes, \& Mamun, 2018; Mamun, Lownes, Bertolaccini, \& Osleeb, 2013). The TOI is a comprehensive measure of transit accessibility that combines spatial coverage, temporal coverage, and trip coverage values. TOI values are calculated between all origin-destination zones but can be summed to create mappable 
origin-based scores as shown in Figure 2 below. Spatial coverage $\left(R_{i l}\right)$ is the proportion of a zone within walking distance $(400 \mathrm{~m})$ of transit stops $\left(\frac{B_{i, l \text { buffer }}}{B_{i, t o t a l}}\right)$. Temporal coverage $\left(S_{i j l}\right)$ is the number of available seats per day between two zones, calculated as the product of the number of times a particular trip $\left(v_{i j l}\right)$ operates and the capacity of the vehicle operating that trip $(U)$. Trip coverage $\left(\delta_{i j l} f_{i j l}\right)$ values between two zones are assigned using a decay function. The decay function $\left(f_{i j}\right)$ assigns a high value of 1 if the trip takes less than 10 minutes and decreases the value for longer trips. To calibrate the decay function, it is also assumed the value for a 60 minute trip will equal the proportion of commuters whose trip to work is longer than 60 minutes. For example, if 10 percent of people commute longer than 60 minutes to work, a 60 minute trip would be assigned a coverage value of 0.10 . For more details on calibrating the decay function, please refer to (Mamun, Lownes, Bertolaccini, \& Osleeb, 2013). Higher TOI values indicate higher levels of transit accessibility. Earlier versions of the TOI normalized values across a service area to allow for easier interpretations of the scores. Unfortunately, the normalization process hinders the ability to make longitudinal comparisons so the TOI scores will be left in their raw form with units of adjusted seats per day.

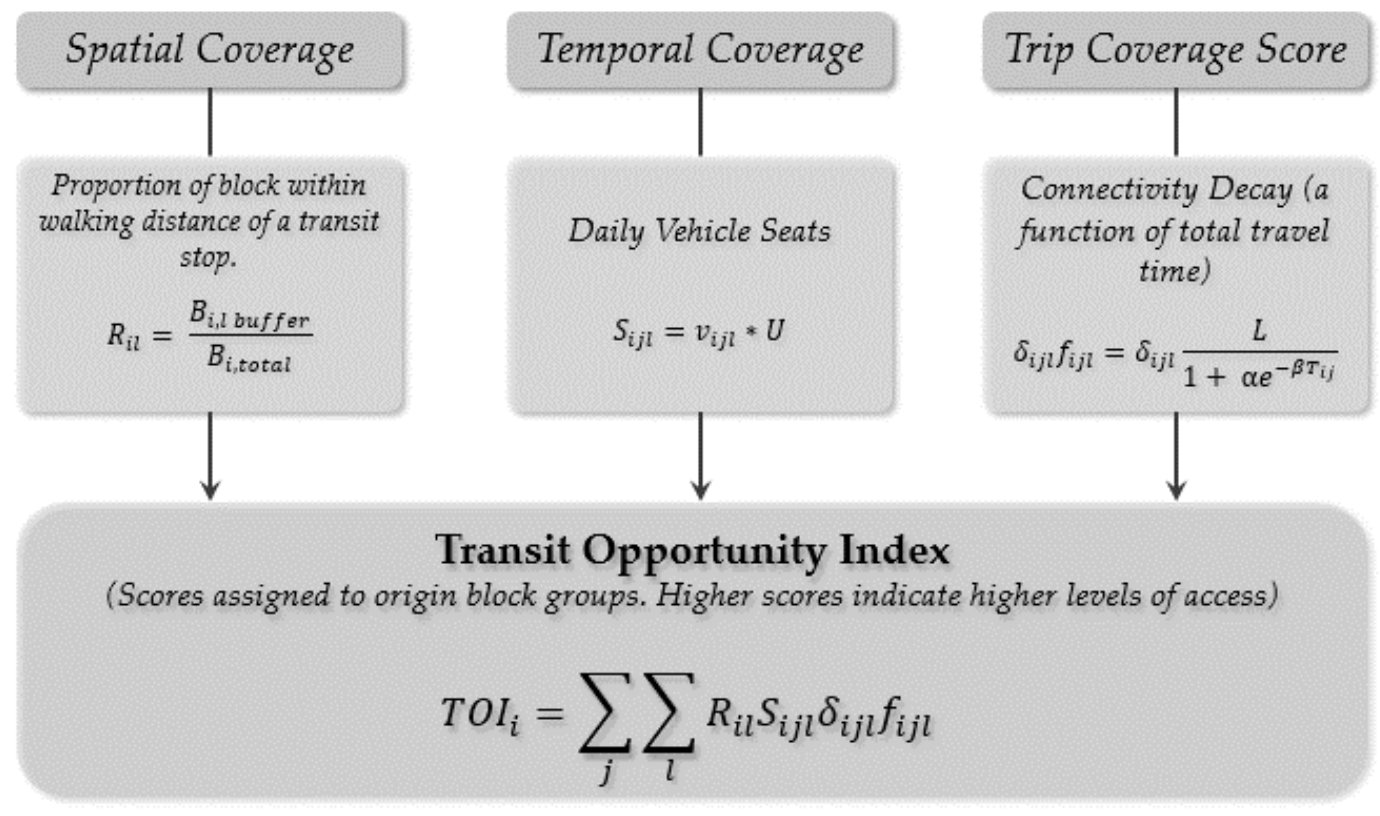

Figure 2: Calculating Transit Opportunity Index

The equity of transit accessibility are measured using the Transit Gini coefficient developed by (Delbosc \& Currie, 2011). Unlike the traditional Gini coefficient that uses a Lorenz curve to represent the relationship between cumulative population and cumulative proportion of wealth, the Transit Gini uses a Lorenz curve to represent the relationship between the cumulative transit demand and the cumulative transit supply. TOI will be used as the measure of transit supply and the sum of population and employment will serve as a proxy for transit demand. While Gini coefficients are attractive for their ability to simplify a large amount of data into a single number, they can obscure underlying spatial and demographic patterns. To address this issue, maps showing changes in TOI will supplement the Gini coefficients.

This analysis relies on several sources of data. The schedule and network structure of the CTtransit Hartford bus system are derived from the static GTFS feeds (Google, 2015). CTtransit publishes their GTFS feeds on a public website (CTtransit, 2016), though they do not archive older feeds. The U.S. 
Census Bureau created the demographic data on population, race, ethnicity, and poverty used in this analysis (U.S. Census Bureau, 2015a), as well as the block group shapefiles (U.S. Census Bureau, 2010). Longitudinal Employer Household Dynamic (LEHD) data is used to develop the jobs specific TOI and Transit Gini (U.S. Census Bureau, 2015b; U.S. Census Bureau, 2015c).

\section{Case study results}

\subsection{Overview of changes to CTtransit Hartford between 2013 and 2016}

As discussed in the introduction, the primary change to the Hartford bus system in this three year period was the addition of a dedicated busway connecting the Hartford CBD to New Britain, a town approximately $16 \mathrm{~km}(10 \mathrm{mi})$ southwest of the city. At the same time, CTtransit restructured routes and schedules across the entire system. One of the most noticeable changes was the addition of 11 new routes and the overall increase in trips. No routes were removed from the pre-CTfastrak system. CTtransit Hartford operated 26\%, 51\%, and 98\% more trips in 2016 than 2013 on weekdays, Saturdays, and Sundays, respectively. It is unclear whether these changes were directly related to the opening of the busway. Figure 3 shows the changes in weekday service frequency on routes between 2013 and 2016.

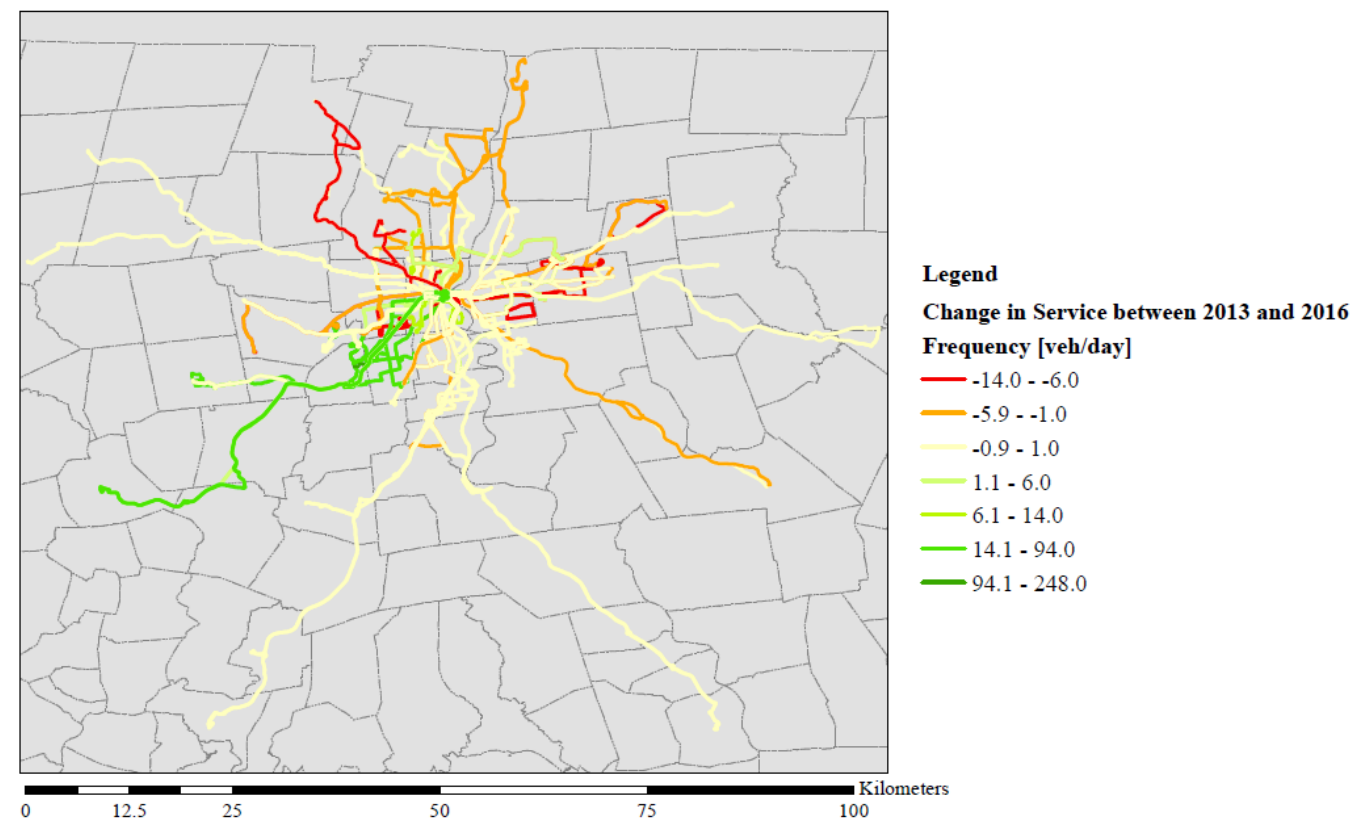

Figure 3: Change in the number of vehicles per day on each route in the CTtransit Hartford system between 2013-2016

As expected, the largest increases in services are found on the busway and surrounding routes. The highest concentration of decreasing service frequency is to the north and northwest of the Hartford CBD along the I-91 corridor. Frequency of service to the east was relatively stable to the east with a few exceptions. These patterns shifted on the weekend with increases in service frequencies being experienced more broadly across the system.

Overall transit accessibility increased as well. The sum of TOI values for the system increased from 2.02 billion adjusted seats per day to 3.15 billion adjusted seats per day, an increase of just over 55\%. Figure 4 below shows the distribution of TOI values in 2013 and 2016. 


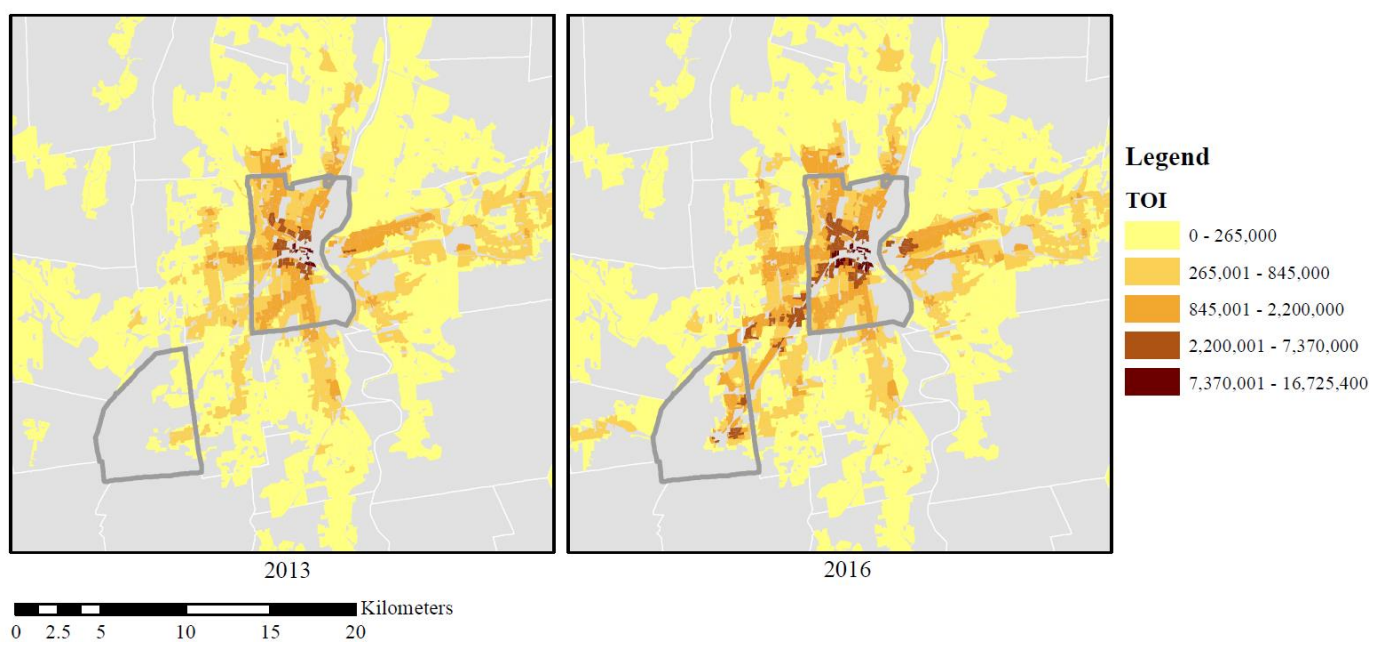

Figure 4: Changes in block level Transit Opportunity Index values from 2013-2016

The increases in service frequencies and TOI values make a strong case that system-wide transit accessibility improved dramatically in the CTtransit Hartford service area between 2013 and 2016. However, these improvements were not equally distributed among the region. Figure 5 below maps changes in TOI across the system between 2013 and 2016.

The greatest improvements in transit opportunity were along the I-84 corridor. While the improvements in transit access along the busway were expected, the improvements to transit access on the eastern portion of the corridor were a surprise. Figure 3 (service change map) shows that most routes in this region either maintained or lost service frequency during this time period. The increase in TOI is explained by an improvement in trip coverage from the addition of the busway. Routes servicing this town (East Hartford) are now able to reach destinations along the busway in under an hour, an option that was infrequently available prior to the busway. 


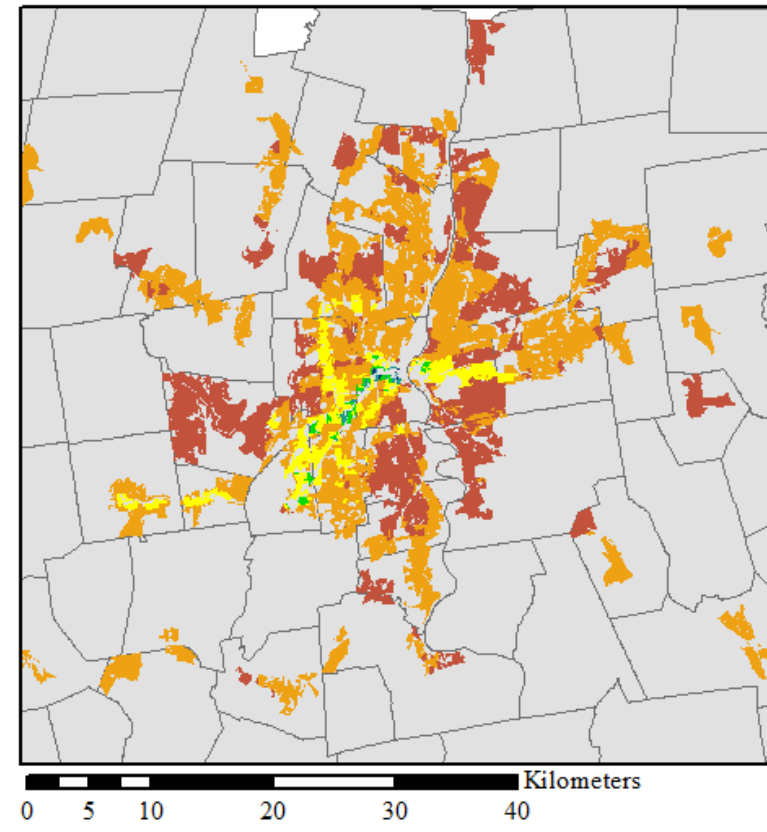

\section{Legend}

Change in TOI between 2013-2016

$-220,000-0.0$

$0.010-220,000$

$230,000-1,700,000$

$1,800,000-3,800,000$

$3,900,000-7,200,000$

$7,300,000-13,000,000$

Figure 5: Change in Transit Opportunity Index from 2013 to 2016

\subsection{Changes in equity}

The Transit Gini coefficient increased slightly from 0.62 to 0.65 from 2013 to 2016, indicating slightly worsened horizontal equity in the transit service area. The significance of the increase, particularly given its relatively small size, is unclear. The addition of a busway along a portion of one specific corridor will result in an uneven distribution of new transit access and worsen horizontal equity measures in nearly all cases.

Another important consideration is the effect of the system changes on vulnerable populations. This analysis considered impoverished communities and communities of color. Figure 6 below shows the distribution of households living below the poverty threshold and people identifying as races and ethnicities other than white, non-Hispanic. 

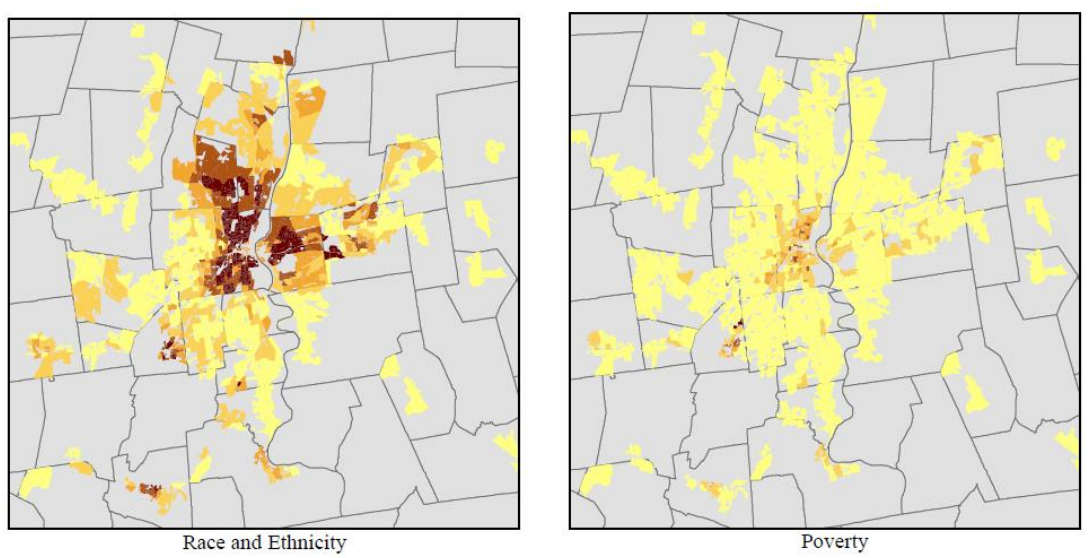

Legend

Percentage of population

$0.00-20.0$

$20.1-40.0$

$40.1-60.0$

$60.1-80.0$

$80.1-100$

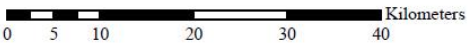

Figure 6: (Left) Distribution of people identifying as a race other than white or as Hispanic; (Right) Distribution of households living below the poverty threshold

Similar to techniques used for Title VI equity analysis, any block whose vulnerable population percentage exceeds the system average is set aside for special analysis. The mean percentage of people identifying as a race or ethnicity other than white, non-Hispanic is 39.36 and the mean percentage of households in poverty is 12.8 . While blocks with high populations of racial and ethnic minorities make up $40.8 \%$ of all blocks in the service area, they accounted for only $28.1 \%$ of the blocks experiencing decreases in transit access and over $53.8 \%$ of those experiencing large increases in access $(>220,000$ increase in TOI). A similar pattern exists for families living in poverty. High poverty blocks account for $33.0 \%$ of all blocks in the service area but only $18.5 \%$ of the blocks experiencing a decrease in TOI and over $51.2 \%$ of blocks with large increases in TOI. This suggests the changes to CTtransit Hartford's network and schedule were an overall gain for impoverished communities and communities of color and an improvement in terms of vertical equity.

\subsection{Changes in access to jobs}

The final equity-related concern this analysis seeks to address is changes in the ability of people to access jobs and services. This final section will briefly explore access to jobs. Future analyses should consider access to other important activities, such as education and healthcare facilities.

The LEHD dataset is used as a source of block level worker data. Figure 7 below shows the distribution of jobs in the Hartford area. The jobs are notably not concentrated in the Hartford CBD, the hub of the transit system. While the dataset does break down jobs by sector and by annual earnings, it does not include pay rate or hours offered so it cannot be used to further determine the quality of the job. 

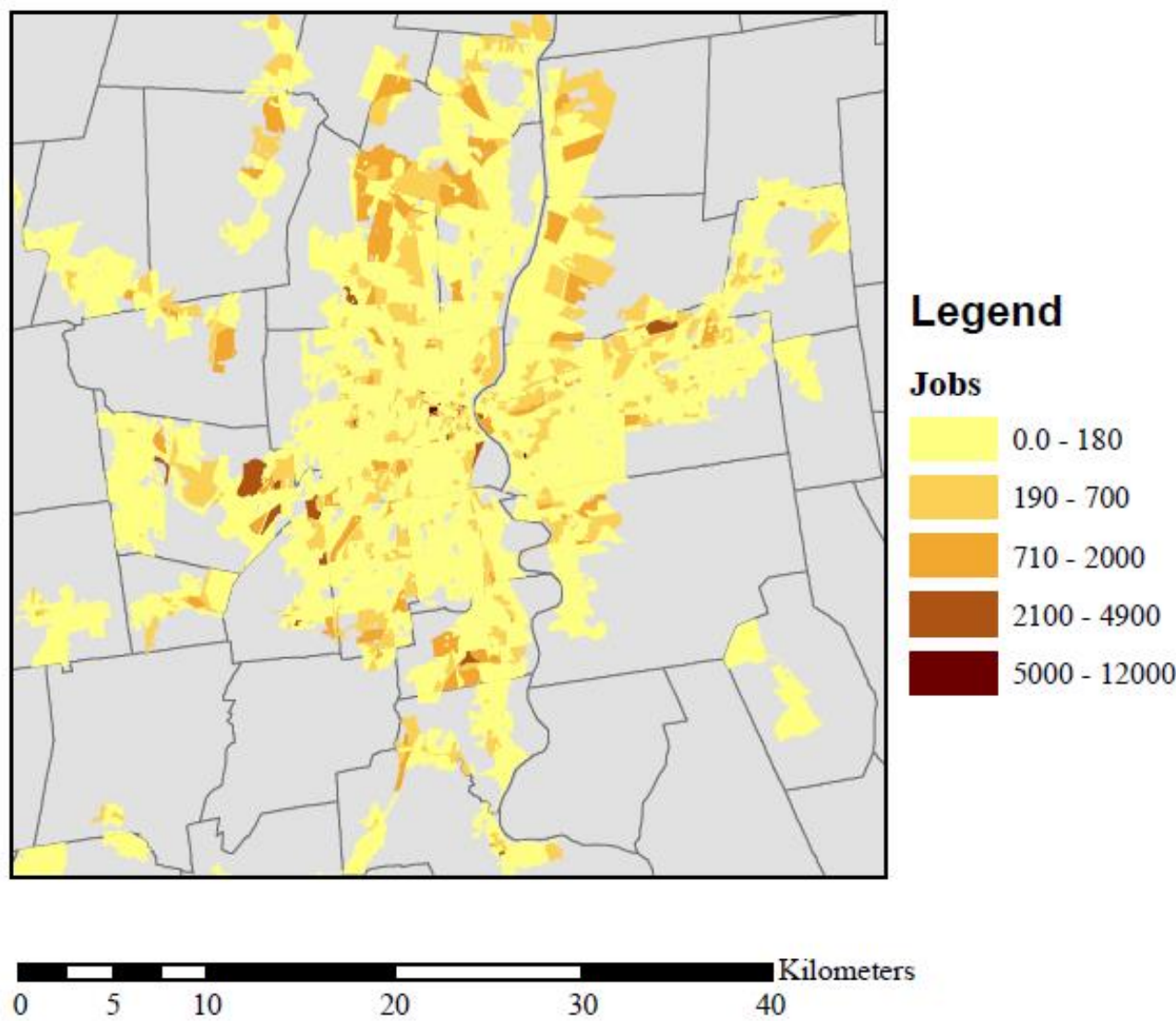

Figure 7: Distribution of jobs in the CTtransit Hartford service area

LEHD dataset also provides worker origin-destination flows. These flows were joined to their associated pairwise TOI values to generate Transit Gini coefficients for 2013 and 2016. Only O-D pairs with worker flows greater than zero are considered in the calculation. The worker-specific Transit Gini also increased from 0.78 to 0.79 . This change is so small it may be meaningless. However, given the overall high value of both Gini coefficients, there is a concern that neither the 2013 nor the 2016 system provide workers with good transit access to their places of work. A visual comparison of Figures 7 and 4 supports this hypothesis, with many of the highest employment blocks located at the outer edge of the service area while high access blocks are located closer to the CBD.

\section{Conclusion}

This analysis provides compelling evidence that transit accessibility improved system wide as a result of CTfastrak and the accompanying service changes between 2013 and 2016. These improvements extend beyond the areas directly impacted by the new infrastructure. The vulnerable populations examined in this study gained more transit access and experienced fewer decreases in transit access than other populations. The jobs accessibility analysis raised some concerns. While the worker-specific Transit Gini changes little from 2013 to 2016, the high Gini coefficients suggests a mismatch between the connections created by the current transit network and the connections people need. The next phase of this case study will seek to examine how well the system actually connects people to specific types of places and services, such as post-secondary education and healthcare. 


\section{References}

Bertolaccini, K., Lownes, N. E., \& Mamun, S. A. (2018, July). Measuring and mapping transit opportunity: An expansions and application of the Transit Opportunity Index. Journal of Transport Geography, 71, 150-160.

Connecticut Department of Transportation. (2016). CTfastrak Year One Report. Newington, CT: CTDOT.

CTtransit. (2016). Developers. Retrieved from https://www.cttransit.com/about/developers

Delbosc, A., \& Currie, G. (2011). Using Lorenz curves to assess public transport equity. Journal of Transport Geography, 19(6), 1252-1259.

Federal Transit Administration. (2015, March 27). U.S. Department of Transportation celebrates opening of Connecticut's first bus rapid transit system. Retrieved from https://www.transit.dot.gov/ about/news/us-department-transportation-celebrates-opening-connecticut $\% \mathrm{E} 2 \% 80 \% 99$ s-firstbus-rapid-transit

Google. (2015). Static transit overview. Retrieved from Google Developers: https://developers.google. $\mathrm{com} /$ transit/gtfs/

Mamun, S., Lownes, N., Bertolaccini, K., \& Osleeb, J. (2013). A method to define transit opportunity space. Journal of Transport Geography, 28, 144-154.

Melone, K. (2006, February 6). Busway rides tough road. Hartford-New Britain express link gathers momentum, detractors. Hartford Courant, p. 1.

Swift, M., \& Good, S. (1999, August 1). Mass transit outlook brighter in city: Busway plan gains support. Hartford Courant, p. 32.

U.S. Census Bureau. (2010). TIGER/line shapefiles. 2010 block groups. Retrieved from https://www. census.gov/geo/maps-data/data/tiger-line.html

U.S. Census Bureau. (2015a). 2014 American community survey 5-year estimates. Retrieved from https://factfinder.census.gov/faces/nav/jsf/pages/download_center.xhtml

U.S. Census Bureau. (2015b). Longitudinal employer-household dynamics: Workplace area characteristics for Connecticut 2014. Retrieved from https://lehd.ces.census.gov/data/

U.S. Census Bureau. (2015c). Longitudinal employer-household dynamics: Origin-destination for Connecticut 2014. Retrieved from https://lehd.ces.census.gov/data/

U.S. Department of Transportation, Federal Transit Administration, \& Connecticut Department of Transportation. (2001). New Britain-Hartford busway, New Britain, Newington, West Hartford, and Hartford counties: Environmental impact statement. Cambridge, MA: FTA Region 1. Retrieved from https://books.google.com.au/books/about/New_Britain_Hartford_Busway_New_Britain. html?id=CyY3AQAAMAAJ\&redir_esc=y

Willingham, T. (2000, March 23). DOT to field questions about proposed busway. Hartford Courant, p. 60 . 